\title{
PKM Pencegahan Pernikahan Usia Dini Pada Siswa SMA Negeri 1 Kampar
}

\author{
Raja Widya Novchi ${ }^{1}$, Khusnul Hanafi ${ }^{1}$, Puti Pebriniko ${ }^{1}$, \\ Aidil Haris ${ }^{1}$, Asrinda Amalia ${ }^{1}$, Almannur ${ }^{1}$, Raja Arlizon ${ }^{2}$ \\ ${ }^{1}$ Universitas Muhammadiyah Riau \\ ${ }^{2}$ Universitas Riau \\ email: rajawidya@umri.ac.id
}

\begin{abstract}
The Center for Gender and Sexuality Studies at the University of Indonesia revealed that the number of underage marriages in Indonesia is quite high, ranking the second top in the Southeast Asian Region. This condition occurs in Kampar Regency, precisely in Air Tiris Village, Kampar District. This area is a fairly densely populated area with various social phenomena occurring in it, one of which is early marriage. From divorce data from the Bangkinang Religious Court, Kampar Regency, it was stated that there were $70 \%$ divorce cases, especially during this Covid-19 period and the plaintiffs were dominated by wives. If this problem is left unchecked, it will lead to various problems such as psychological aspects of adolescents, the economy, the future, health, and the occurrence of population explosion. The implementation of the activity took place from 10-11 October 2020 with 30 participants. The form of problem solving is carried out using socialization, counseling, increasing knowledge, increasing soft skills, mentoring, monitoring and evaluating. Based on the results of the evaluation, observations and direct responses from the participants, this service activity was quite successful considering the increased understanding of the material presented. Participation and responses from participants were also very good, as seen from the many responses and questions asked, including the number of participants, activities, and discussions.
\end{abstract}

Keywords: Early Marriage, Teenagers

\begin{abstract}
Abstrak
Pusat Kajian Gender dan Seksualitas Universitas Indonesia mengungkapkan bahwa angka pernikahan di bawah umur di Indonesia tergolong cukup tinggi yaitu peringkat kedua teratas di Kawasan Asia Tenggara. Kondisi seperti ini terjadi di Kabupaten Kampar tepatnya di Kelurahan Air Tiris Kecamatan Kampar. Wilayah ini adalah daerah yang cukup padat penduduk dengan berbagai fenomena sosial terjadi ddalamnya, salah satunya adalah pernikahan dini. Dari data perceraian dari Pengadilan Agama Bangkinang, Kabupaten Kampar menyebutkan terdapat $70 \%$ kasus perceraian, terlebih pada masa covid-19 ini dan penggugat didominasi oleh istri. Apabila permasalahan ini dibiarkan akan memunculkan berbagai permasalahan seperti aspek psikologis remaja, perekononian, masa depan, kesehatan, dan terjadinya ledakan jumlah penduduk. Pelaksanaan kegiatan berlangsung dari tanggal 10-11 oktober 2020 dengan peserta 30 orang. Bentuk pemecahan permasalahan dilakukan menggunakan sosialisasi, penyuluhan, peningkatan pengetahuan, peningkatan soft skill, pendampingan, monitoring dan evaluasi. Berdasarkan hasil evaluasi, pengamatan dan tanggapan langsung dari peserta, kegiatan pengabdian ini cukup berhasil mengingat adanya peningkatan pemahaman mengenai materi yang disampaikan. Partisipasi dan tanggapan dari peserta juga sangat baik, terlihat dari banyaknya tanggapan dan pertanyaan yang diajukan, termasuk dilihat dari jumlah banyaknya jumlah peserta, keaktifan, dan diskusi..
\end{abstract}

Kata Kunci: Pernikahan Dini, Remaja

PENDAHULUAN

Pada masa peradaban Yunani, wanita sama sekali tidak diberi pendidikan dan peran dalam kehidupan bermasyarakat [1]. Mereka dianggap hina, disebut najis dan penuh dengan perbuatan setan ${ }^{[2]}$. Dalam 
hal Undang-Undang Negara, wanita disamakan dengan harta benda yang boleh dijual maupun dibeli secara terbuka di pasar-pasar. Seumur hidupnya, wanita berada di bawah kekuasaan laki-laki dan wanita tidak diberi kemerdekaan untuk mendapatkan haknya ${ }^{[3]}$. Sementara dalam peradaban Romawi kuno, hak anak perempuan sepenuhnya ditangan sang ayah. Sebagai kepala keluarga, seorang ayah berhak penuh menentukan apakah anak yang dilahirkan sang istri boleh menjadi bagian dari keluarga, atau harus dibuang ${ }^{[4]}$. Seorang anak, terutama anak perempuan, sama sekali tidak memiliki hak atas dirinya sendiri. Jika ayah meninggal, kekuasaan atas anak perempuannya diwasiatkan kepada anak laki-laki sebagai wali seumur hidup ${ }^{[5]}$. Ia hanya bisa lepas dari kungkungan wali apabila menikah dengan laki-laki lain dan secara otomatis, hidupnya berada di bawah kekuasaan suami. Praktek pernikahan dini tidak hanya terjadi pada masa zaman dulu saja, akan tetapi pada zaman modern seperti sekarang ini fenomena pernikahan dini masih terus terjadi di berbagai belahan dunia, dari timur hingga barat ${ }^{[6]}$.

Di Indonesia, pada umumnya pernikahan antara laki-laki dan perempuan dilakukan pada usia yang cukup matang sesuai dengan ketentuan dalam pasal 7 ayat I UU No. I Tahun 1974 tentang perkawinan dapat dilaksanakan apabila pihak laki-laki sudah berusia 19 tahun dan perempuan berusia 16 tahun [7]. Apabila ada salah satu pihak atau keduanya berusia kurang dari ketentuan diatas maka dinyatakan melakukan pernikahan di bawah umur. Undang-Undang Perkawinan dibuat pada 1974 mengalami berbagai pertentangan [8]. Anak dikatakan sudah matang pada umur 16 tahun hanya karena sudah mengalami pubertas, dilihat dari sisi psikologisnya remaja belum bisa berfikir secara jernih dan cenderung tergesa-gesa dalam mengambil sikap maupun keputusan yang nantinya akan dipertanggung jawabkan ${ }^{[9]}$.
Pernyataan ini senada dengan Undang-Undang Perlindungan Anak Nomor 23 Tahun 2002 yang menyatakan bahwa seorang individu yang belum mencapai umur 18 tahun, dikategorikan sebagai anak. Pada tahun 2015 Pusat Kajian Gender dan Seksualitas Universitas Indonesia mengungkapkan bahwa angka pernikahan di bawah umur di Indonesia tergolong cukup tinggi yaitu peringkat kedua teratas di Kawasan Asia Tenggara [10]. Perempuan Indonesia yang berumur di bawah 15 tahun sekitar 7,3 juta dan sekitar 2 juta diantaranya sudah menikah dan tidak melanjutkan pendidikan bahkan ada yang putus sekolah [11]. Hal tersebut turut didukung oleh UNICEF pada tahun 2001 yang menyatakan pasangan muda melakukan pernikahan di bawah umur 18 tahun dinyatakan belum siap secara fisik, fisiologis, psikologis, terutama tidak siap untuk memikul tanggung jawab menikah dan melahirkan anak ${ }^{[12] .}$

Seseorang yang melakukan pernikahan pada usia dini membawa berbagai dampak seperti dalam dunia pendidikan.Selain itu belum lagi masalah ketenagakerjaan, realitanya yang ada di tengah masyarakat, seseorang yang memiliki pendidikan rendah hanya dapat mendapatkan pekerjaan biasa bahkan dapat kita lihat banyaknya buruh berpendidikan rendah. Dari segi kesehatan dampak yang ditimbulkan oleh pernikahan dini yaitu penyakit kandungan antara lain infeksi kandungan dan kanker mulut rahim. Penyebab ini terjadi karena masa transisi sel anak-anak ke sel dewasa yang terlalu cepat. Sedangkan dari segi psikologis, pernikahan dini dapat mengurangi harmonisasi rumah tangga yang disebabkan oleh keinginan untuk menikmati masa muda, emosi yang tidak bisa dikontrol, tidak bisa mengambil keputusan dengan tepat dan cara berpikir yang belum matang.

Kondisi seperti ini terjadi di Kabupaten Kampar tepatnya di Kelurahan Air Tiris Kecamatan Kampar. Wilayah ini 
adalah daerah yang cukup padat penduduk dan berbagai fenomena sosial terjadi ddalamnya, salah satunya adalah pernikahan dini. Dari observasi tim pengabdibanyak faktor penyebab terjadinya pernikahan usia dini antara yaitu pola pikir zaman primitif yang dibuktikan dengan sebuah paradoks perkawinan antara pilihan orang tua dengan kemauan sendiri, faktor ekonomi, ingin melanggengkan hubungan, dan faktor yang sebenarnya tidak dikehendaki yaitu MBA (married by accident) menikah karena kecelakaan. Dalam hal ini, sepasang laki-laki dan perempuan terpaksa menikah di usia muda karena perempuan telah hamil duluan di luar nikah. Kantor urusan Agama (KUA) Kabupaten Kampar dari tahun 2017-September 2019 mencatat sebanyak 835 pasangan menikah muda dan didapatkan data perceraian dari Pengadilan Agama Bangkinang, Kabupaten Kampar menyebutkan sejumlah 246 kasus perceraian.Apabila permasalahan ini dibiarkan akan memunculkan berbagai permasalahan seperti aspek psikologis remaja, masa depan, kesehatan, dan terjadinya ledakan jumlah penduduk. Dari latar belakang diatas maka tim pengabdi berinisiasi membuat kegiatan pengabdian di Kelurahan Air Tiris agar remajanya paham mengenai dampak negatif dari pernikahan dini, lebih bijak menggunakan media sosial, tim pengabdi turut memberikan soft skill tambahan berupa public speaking.

\section{METODE PENGABDIAN}

Metode pelaksanaan dilakukan dengan berbagai tahapan, antara lain yaitu:

1. Survey Lapangan

Persiapan yang kami lakukan dimulai dengan melalukan kegiatan survey lapangan dan wawancara kepada penduduk setempat sebelum merumuskan program-program yang akan dilakukan. Setelah mengetahui keadaan desa dan keadaan penduduknya, kemudian kami merumuskan tema kegiatan dan menyusun program kerja dalam bentuk proposal sesuai dengan hasil observasi

2. Persiapan

Persiapan meliputi pengumpulan informasi terkait dengan kegiatan pengabdian, data-data di kelurahan dan materi dari sumber terpercaya yang akan digunakan. Adapun tahap persiapan yang kami lakukan adalah sebagai berikut:

a. Pengenalan wilayah, penduduk dan pencarian solusi

b. Meminta izin dengan perangkat kelurahan Air Tiris

c. Kerjasama dengan mitra yaitu SMAN 1 Kampar

3. Penyusunan Program Kerja

Program kerja utama yang telah disusun sebelumnya melibatkan ketua, anggota dan 2 (dua) orang mahasiswa. Setiap tim yang terlibat mendapatkan desk job masing-masing agar kegiatan pengabdian berjalan dengan lancar seperti yang diharapkan. Penyusunan program kerja disesuaikan dengan permasalahan yang ada di Kelurahan Air Tiris yaitu banyaknya remaja yang menikah pada usia dini dan kurangnya soft skill siswa SMAN1 Kampar.

Tim pengabdi membuat tiga kegiatan antaranya yaitu:

1. Pemaparan materi penyuluhan pernikahan dini berupa tayangan video dan metode ceramah. Setelah dilakukan penyampaian materi oleh narasumber dilanjutkan dengan sesi tanya jawab oleh peserta.

2. Memberikan seminar dengan tema bijak menggunakan media sosial di kalangan remaja.

3. Pelatihan soft skill public speaking untuk siswa SMAN 1 Kampar

Kegiatan pengabdian dilaksanakan di SMAN 1 Kampar. Pelaksanaan kegiatan dilaksanakan selama 2 (dua) hari dengan jumlah pesertalebih kurang 30 orang. Bentuk pemecahan permasalahan (problem solving)dilakukan dengan beberapa pendekatan yaitu: sosialisasi, 
penyuluhan, peningkatan pengetahuan, peningkatan soft skill, pendampingan, monitoring dan evaluasi.

\section{HASIL DAN PEMBAHASAN}

Kegiatan pengabdian kepada masyarakat ini merupakan salah satu upaya untuk memberikan pengetahuan, informasi, pemahaman dan penyadaran kepada masyarakat yang dalam hal ini adalah remaja mengenai pentingnya memahami tentang pernikahan dini. Kegiatan telah dilakukan oleh Tim pengabdian di SMAN 1 Kampar. Pada pengabdian masyarakat ini berusaha membantu masyarakat Kelurahan Air Tiris Kecamatan Kampar mengurangi tingkat pernikahan dini yang tinggi yang terjadi di wilayah tersebut. Pelaksanaan pengabdian telah dilaksanakan pada hari SabtuMinggu 10-11 Oktober 2020 dengan jumlah peserta kurang lebih 30 orang.Kegiatan pengabdian kepada masyarakat ini dilaksanakan secara bertahap, meliputi 2 tahap, yaitu: Tahap pertama pada bulan September-Oktober 2020, Tim Pelaksana dengan didampingi mahasiswa Fakultas Ilmu Komunikasi mengunjungi lokasi pengabdian untuk melakukan perizinan dan memaparkan tentang bentuk kegiatan yang akan dilakukan yaitu mengurangi tingkat pernikahan dini yang tinggi yang terjadi di Kelurahan Air Tiris sekaligus mengadakan observasi tentang wilayah dan pendudukagar sesuai dengan denga target pengabdian.

Tahap kedua pada tanggal 10-11 Oktober 2020,tim pengabdian mulai mengadakan sosialisasi dan penyuluhan tentang pentingnya pencegahan pernikahan dini. Kegiatan ini dilakukan dengan cara memaparkan materi melalui metode ceramah, tayangan video dan tanya jawab. Pada Tahap kedua ini dihadiri oleh Perangkat Kelurahan Air Tiris. Kegiatan pengabdian ini diawali dengan pembukaan acara oleh mitra. Beliau memperkenalkan Tim Pengabdian dari Universitas
Muhammadiyah Riau yang akan mengisi materi pengabdian dengan tema pencegahan pernikahan dini, seminar bijak bermedia sosial dan pelatihan soft skill public speaking. Kemudian Ketua Tim Pengabdian Raja Widya Novchi, M.Soc.Sc memberikan sambutan, ucapan terima kasih karena tim pengabdi telah diberikan kesempatan dan waktu. Selanjutnya, pemberian materi pengabdian oleh Putri Febri Niko, M.Psi Psikolog dan Khusnul Hanafi, M.Soc.Sc

Foto kegiatan pengabdian dapat dilihat dari kumpulan gambar berikut ini:

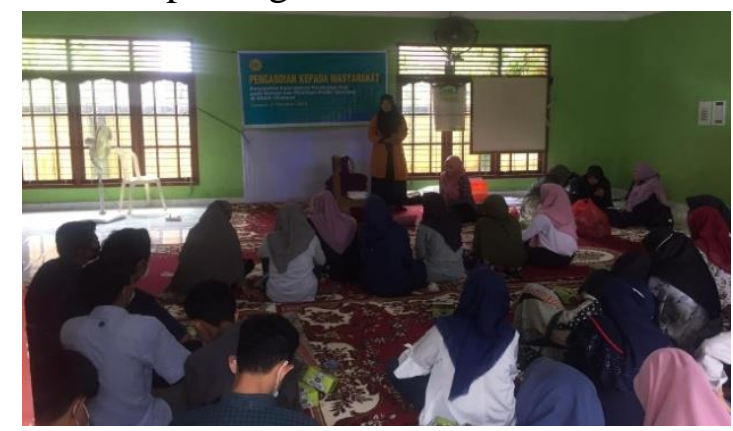

Gambar 1. Penyampaian materi tentang pernikahan dini

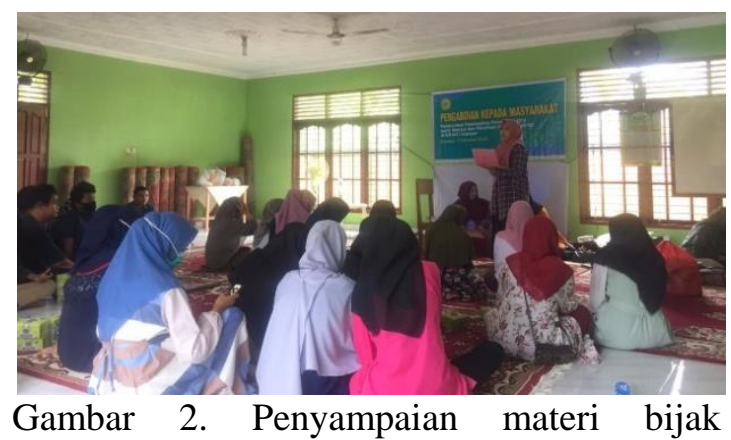
bermedia sosial

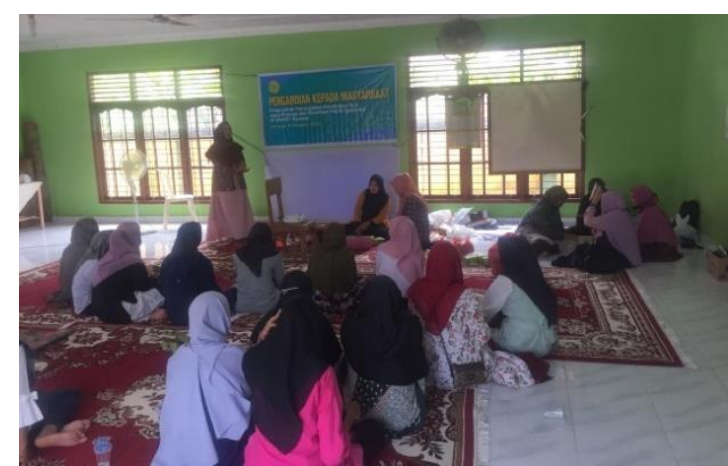

Gambar 3. Pelatihan soft skill public speaking 


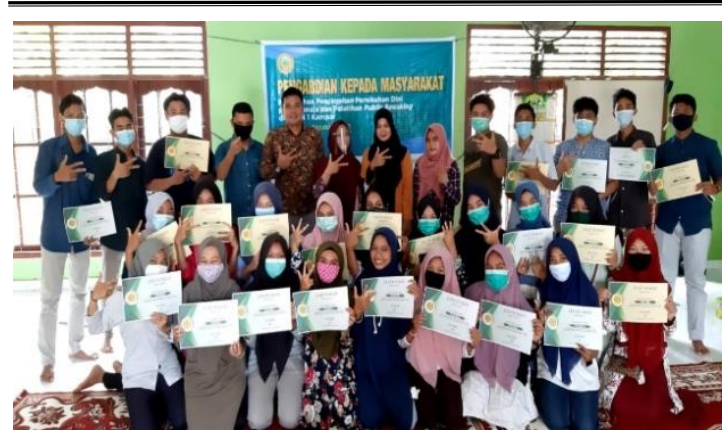

Gambar 4. Foto Bersama dengan Mitra, Kelurahan dan Peserta

\section{SIMPULAN}

Dari hasil evaluasi, pengamatan dan tanggapan langsung dari para peserta, hasilnya kegiatan pengabdian ini cukup berhasil mengingat adanya peningkatan pemahaman mengenai pentingnya pencegahan pernikahan dini, bijak bermedia sosial. Selain itu, pelatihan public speaking turut dipandu oleh mahasiswa Fakultas Ilmu Komunikasi dan memberikan pendampingan kepada peserta. Partisipasi dan tanggapan dari peserta juga sangat baik, terlihat dari banyaknya tanggapan dan pertanyaan yang diajukan, termasuk dilihat dari jumlah banyaknya jumlah peserta, keaktifan, dan diskusi.

\section{UCAPAN TERIMAKASIH}

Ungkapan terima kasih ditujukan kepada Universitas Muhammadiyah Riau sebagai pemberi dana pengabdian internal, SMAN 1 Kampar selaku mitra dari tim pengabdi dan Perangkat Kelurahan Air Tiris yang membantu tim pengabdi dari awal survey sampai terlaksananya kegiatan pengabdian.

\section{DAFTAR PUSTAKA}

[1]. Montazey, S. at all. 2016. Determinants of Early Marriage from Married Girls' Perspectives in Iranian Setting: A Qualitative Study.Journal of Enviromental and Public Health: 1-9.

[2]. Ijeoma, O.C., at all. 2013. Education an Antidote against Early Marriage for the Girl-Child. Journal of
Educational and Social Research. Vol 3(5): 73-78.

[3]. Kezine, S. Marian, E.H. 2017. Effect of child marriage on girls' school dropout in Nepal: Analysis of data from the Multiple Indicator Cluster Survey 2014. Journal Poune. P: 113.

[4]. Banji, S.M., \&Neelam., S.P., 2014. Determinants of Child (Early) Marriages among Young Girls- A Public Health Issue.Journal of Women't Health Care. Vol 3(3): 1-3.

[5]. Djamilah, Reni.K. 2014. Dampak Perkawinan Anak di Indonesia.Jurnal Studi Pemuda. Vol 3(1): 1-16.

[6]. Hadiono, A.F. 2018. Pernikahan Dini dalam Perspektif Psikologi Komunikasi. Jurnal Darussalam, Jurnal Pendidikan, Komunikasi dan Pemikiran Hukum Islam. Vol 9 (2): 385-397.

[7]. Sardi, Beteq. 2016. Faktor-Faktor Pendorong Pernikahan Dini dan Dampaknya di Desa Mahak Baru Kecamatan Sungai Boh Kabupaten Malinau.E Journal Sosiatri Sosiologi. Vol 4 (3): 194-207.

[8]. Syukaisih. 2017. Perilaku Pernikahan Dini pada Remaja di Kecamatan Marpoyan Damai Kota Pekanbaru.Jurnal Penelitian Kesehatan Forikes. Vol 8 (3): 156160.

[9]. Rahman F., Meitria, S., Rakhmy, A., Heppy D.A., 2015. Kajian Budaya Remaja Perilaku Pernikahan Dini di Kota Banjarbaru Kalimantan Selatan. Jurnal MKMI. P: 108-117.

[10]. http://www.koranjakarta.com/pernikahan-dinitimbulkan-masalah/

[11]. https://www.fimela.com/parenting/r ead/3813248/fenomena-menikahterlalu-muda-anak-kehilanganbanyak-haknya

[12]. Hurlock \& Elizabeth. B. 2006. Psikologi Perkembangan. Jakarta: Erlangga 